\title{
Indonesia Wind Power Energy Study
}

\section{Agus Winarso P*}

State College Meteorology \& Geophysics of Indonesia, Indonesia

*Corresponding author: Paulus Agus Winarso, State College Meteorology \& Geophysics of Indonesia, Kompleks Meteorologi-Perhubungan Jl. Pemancar 8/37, Pd. Betung - Pd. Aren Tangerang 15221, Indonesia, Tel: 62 - 21-7355442; E-mail:

\section{Review Article}

Volume 1 Issue 2

Received Date: August 30, 2017

Published Date: October 10, 2017

DOI: $10.23880 /$ jenr-16000112 pawinarso@gmail.com

\section{Abstract}

The most common statement on wind energy in Indonesia is that there is no such thing in the country such that lack of the data and information regarding the wind pattern. That is not convincing, most people who might involve in the development wind energy conversion having difficulty. The other view that most the people pay attention and made them curious of the true potential for renewable power from wind in a country that covers a vast area of tropical seas like Indonesia. As the wind is the driving force behind sailing ships and wind turbine generators (WTG). Indonesia is a country of diverse landscape, ethnic groups and historical development and less meteorological data to be used for wind energy conversion. Not all aspects of life can be considered, this study tries to give an insight the general wind pattern for Indonesia's area. This study attempts to explore wind condition from 10 years period of data in Indonesia Maritime Continent area. As the wind is mostly generated by the difference pressure from two different places, the pressure difference of the so called pressure gradient is responsible for generating wind over earth's surface. Several aspect of the theoretical background from meteorological science may introduce in this study to make clear, in the effort for obtaining general description potential wind to convert into the electric power.

Keywords: Wind energy; Energy conversion

\section{Introduction}

The use of wind power is almost as old as recorded history. The Egyptians used sails to power their boats on the Nile River over 5,000 years ago. The Chinese are thought to have been the first to use windmills, and the Persians are known to have built windmills in 200 B.C. The Persian vertical shaft windmill, or "panemone," was used to power grain-grinding stones. Medieval Europeans used windmills for a wide range of activities, including pumping water, sawing wood, grinding grain, and pressing oil-in fact virtually any process that required mechanical energy. The traditional windmill was developed to its greatest extent by the Dutch, who used windmills by the thousands years ago.

Wind power is the conversion of wind energy into a useful form of energy, such as using: wind turbines to convert the electricity, windmills for mechanical power, wind pumps for water pumping or drainage or sails to propel the ships [1]. Wind power, as an alternative to fossil fuels is plentiful, renewable, widely distributed, clean, produces no greenhouse gas emissions during the operation and uses a little land. The overall cost per unit of energy produced is similar to the cost for new coal and natural gas installation. Any effects on the environment 
are generally less problematic than those from other power sources. Although wind power is a popular form of energy generation, the construction of wind farms in not universally welcomed. Although a variable source of power, the intermittency of wind seldom creates problems when used to supply up to $20 \%$ of total electricity demand, but as the proportion increases problems arise such as: increased costs, a need to use storage such as pumped-storage hydroelectricity, a need to upgrade the grid, or a lowered ability to supplant conventional production. Power management techniques such as: excess capacity storage, dispatch-able backing supply (usually natural gas), exporting and importing power to neighboring areas or reducing demand when wind production is low, can mitigate these problems [2].

Wind is the movement of air across the surface of the Earth, from areas of high pressure to areas of low pressure. The surface of the Earth is heated unevenly by the Sun, depending on factors such as the angle of incidence of the sun's rays at the surface (which differs with latitude and time of day) and whether the land is open or covered with vegetation. Also, large bodies of water, such as the oceans, heat up and cool down slower than the land. The heat energy absorbed at the Earth's surface is transferred to the air directly above it and, as warmer air is less dense than cooler air, it rises above the cool air to form areas of high pressure and thus pressure differentials. The rotation of the Earth drags the atmosphere around with it causing turbulence. These effects combine to cause a constantly varying pattern of winds across the surface of the Earth [3].

Indonesia archipelago lies in the tropical area to be extending from 90 - 160 degrees longitude and 12 degrees South -8 degrees North latitude such that most of the area over the equator. According to the global circulation pattern, the equatorial area is the place for the low pressure with the wind from both hemispheres to meet or of the so called "Inter Tropical Convergence Zone". In another scientific point of view with impact of the earth rotation of the so called Coriolis Force where over the northern hemisphere the particles movement may be deflected to the right hand side perpendicular with the movement and reversal condition over southern hemisphere. What happen with Indonesia area is extending over the equator with some part over northern hemisphere and other part over the southern hemisphere such that the wind shift or wind calm may prevail all time of the year over the equator line. This condition should be encountered or determined when the wind may be used as the power for the electricity. Based upon them, this paper would like to explore the general meteorological study over Indonesia area with focusing the mapping of the potential wind power for the electricity.

\section{Methodology}

The evaluation of wind power energy study is conducted by a sequence of steps which represent restrictions on the exploitation of the meteorological data and theory. In the first step, the theoretical wind blowing over most of the region, where Indonesia archipelago lies in the tropical region with the mostly having of low in speed due to the converging of the wind over both hemispheres. This first approach is based upon the global general circulation as the primary starter for the wind blowing over the earth's surface. The data were used in this study from Meteorological and Geophysical Agency in Indonesia that they derived from direct observation combination with others technique. After taking consideration the wind data in term of gridding of wind data to be used.

In another point it is arrived from the wind blowing to be based upon the pressure gradient force, where increasing number of pressure difference between of the two pint may give increasing wind speed between the two points. As the tropical area closed to the equator line having almost the homogeneous of the surface pressure, this condition may not encourage the wind blowing with increasing number of the speed. Another world most of the area of maritime continent area closed to the equator line may have been calm of low speed of the wind, except of the outer side of the area, there may be favorable wind blowing development. The description of the initial wind and global general circulation may be presented in the figures 1 and 2 in the next discussion.

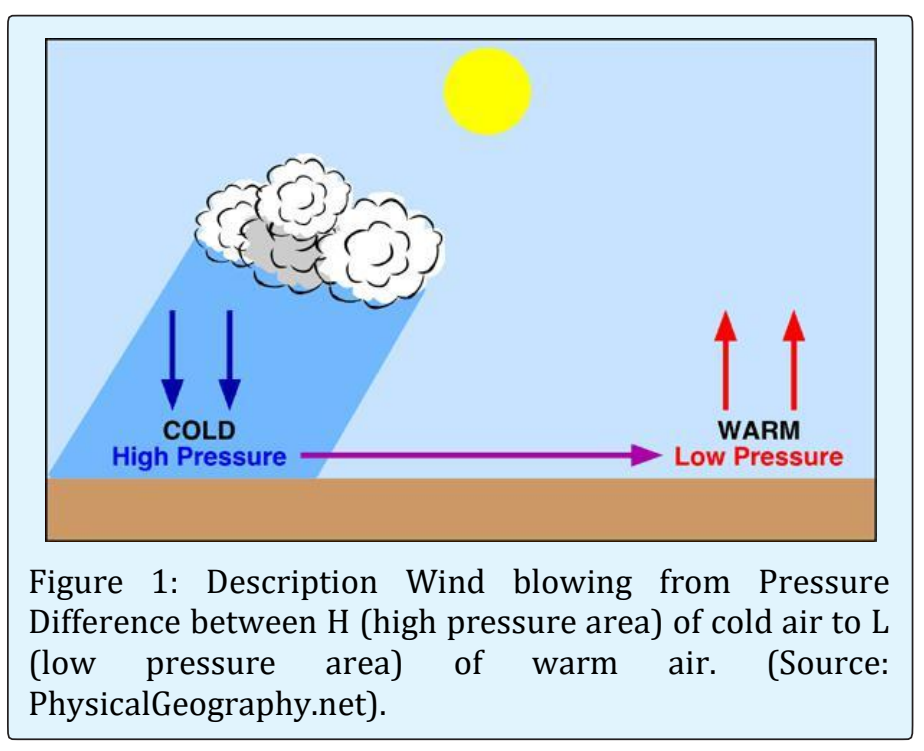




\section{Journal of Ecology \& Natural Resources}

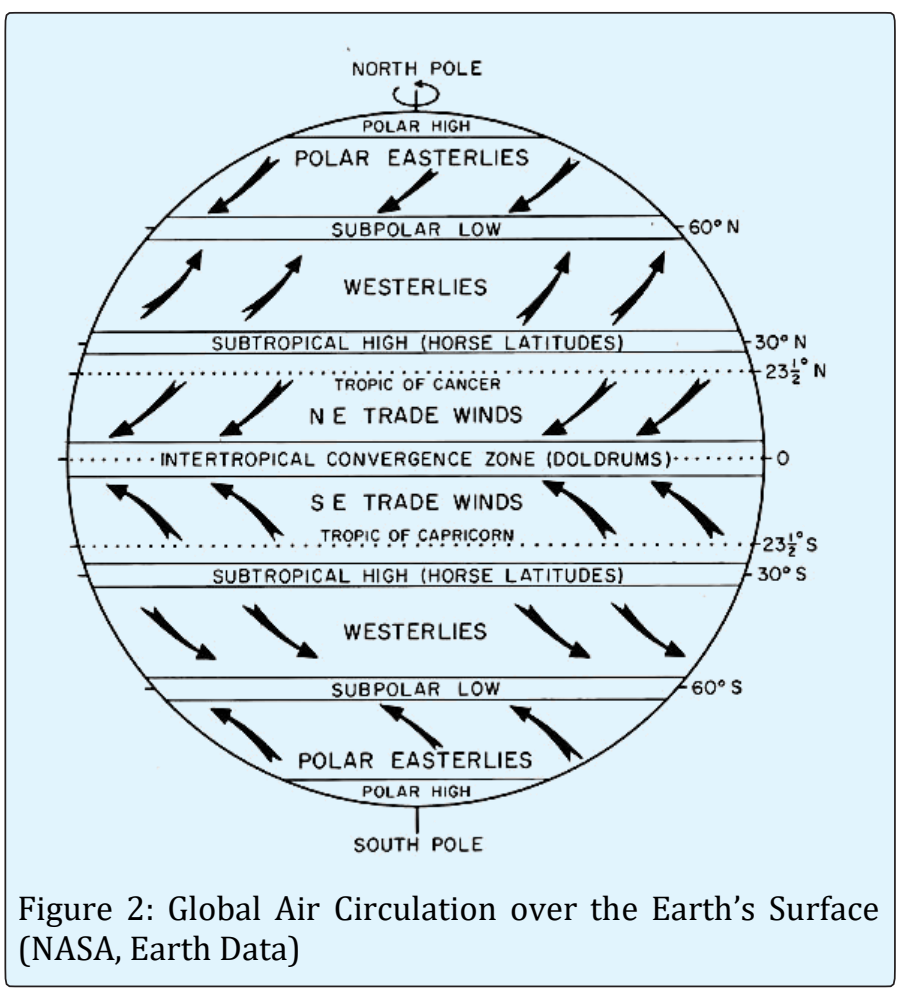

Indonesia maritime continent area has the seasonal wind blowing of the so called monsoonal wind; with almost one period (approaching 4 months) have certain wind blowing and another period with changing reversal direction. Two months period would like to differentiate between the seasonal wind blowing of the so called the transitional wind blowing of the monsoonal wind over maritime continent area of Indonesia. These transitional winds blowing are mostly the low speed or calm wind condition such that this may not support the power wind energy to be used for the electricity purpose. Another aspect with the monsoonal wind blowing may create the wind shift mostly over the equator line such that area over the equator line may be characterized by the low speed or calm wind. Another factor such that equator is the boundary between of the two hemisphere where coriolis force has the different deflection of the wind flow, as transitional area may cause the calm wind over equator line area. This condition is parallel with theoretical global general air circulation that has responsibility for developing wind over global perspective of the wind blowing for power wind energy. The situation of the wind from each monsoonal wind may be presented in the next figure 3 as follows,
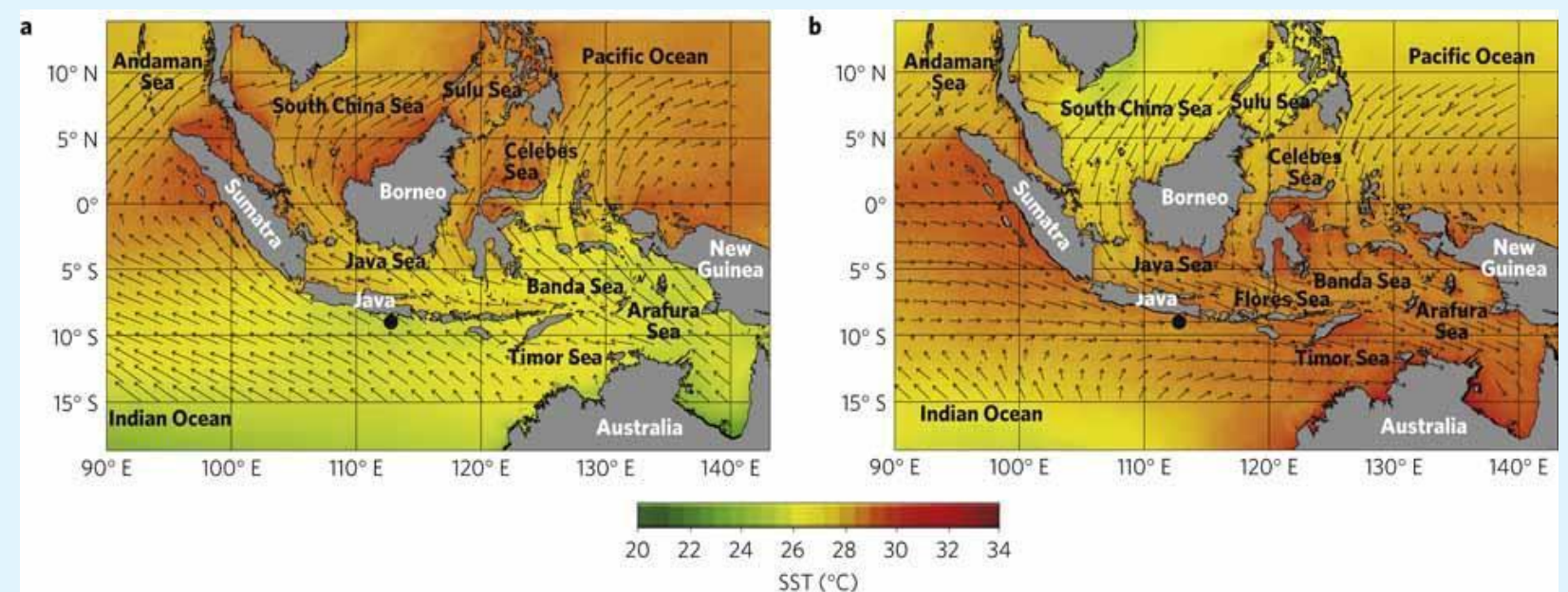

Figure 3: Detail Monsoonal Wind Pattern from each consecutive monsoonal wind, in the surface level (BMG)

Exploring deeply for the wind blowing to be used for power wind energy over Indonesia maritime continent, the global and regional scale of the wind blowing may encourage the idea that area closing with the equator line having less power than over the outer both border with northern and southern hemisphere. This would be discussed in the next discussion.

\section{Discussion}

Indonesia archipelago lies mostly in the tropical area extending from 7 degrees North up to 12 degrees South latitudes and 96 degree East to 158 degrees East longitudes, having the monsoonal wind system of the so called Easterly Monsoonal Wind System during June - 


\section{Journal of Ecology \& Natural Resources}

September and reversal condition of Westerly Monsoonal Wind System during December - March yearly. For October - November period is the transition period wind from easterly into westerly direction as well as for April May is the transition period wind from westerly into easterly direction. These regional wind system may be added with the local wind system due to the existing sealand breeze and mountain-valley wind, they may add some complexity such that most the area having less of the wind especially over the inner (closed with the equator line). The description from operational monsoonal wind system can be shown in the next figures as follows,
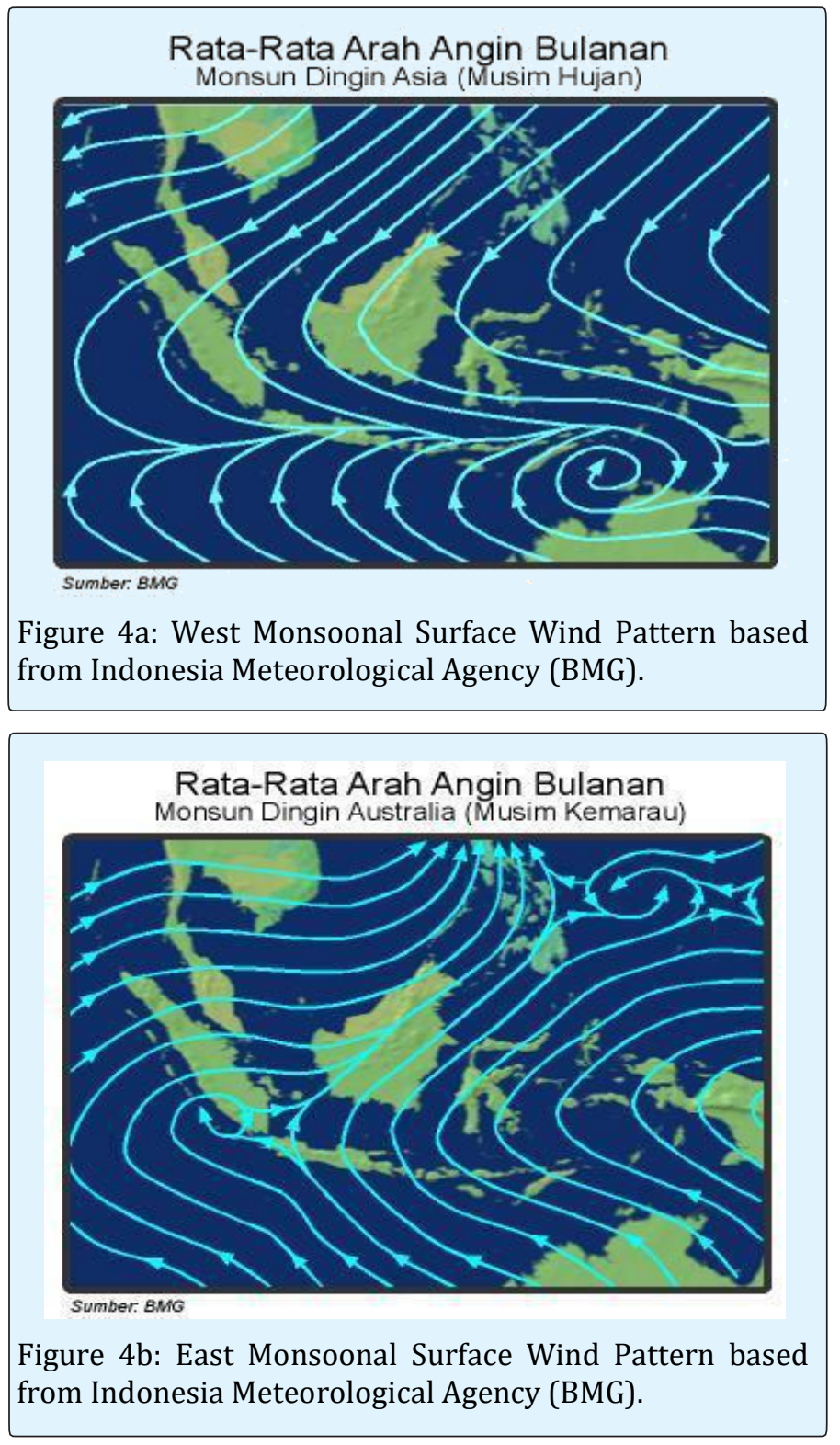

Based upon the seasonal wind system of the monsoonal wind system over Indonesia archipelago, there are two general winds blowing such as westerly and easterly wind system yearly. Westerly wind system may prevail during Northern hemisphere Winter Season (High Pressure) and Southern hemisphere Summer Season (Low pressure) reversal condition for easterly wind system.

Exploring meteorological condition may arrive for identification of the strong wind speed, where outer side of Indonesia archipelago may have a little bit surface pressure gradient force as the trigger for existing wind blowing. This wind blowing is more steady and to be sustain for used as the wind power for the electricity. Based upon the processing yearly wind data for the period 1981 - 1990 with wide of the grid 1 degree latitude $x 1$ degree longitude may give coarse grid value of the wind speed yearly over Indonesia archipelago as follows,

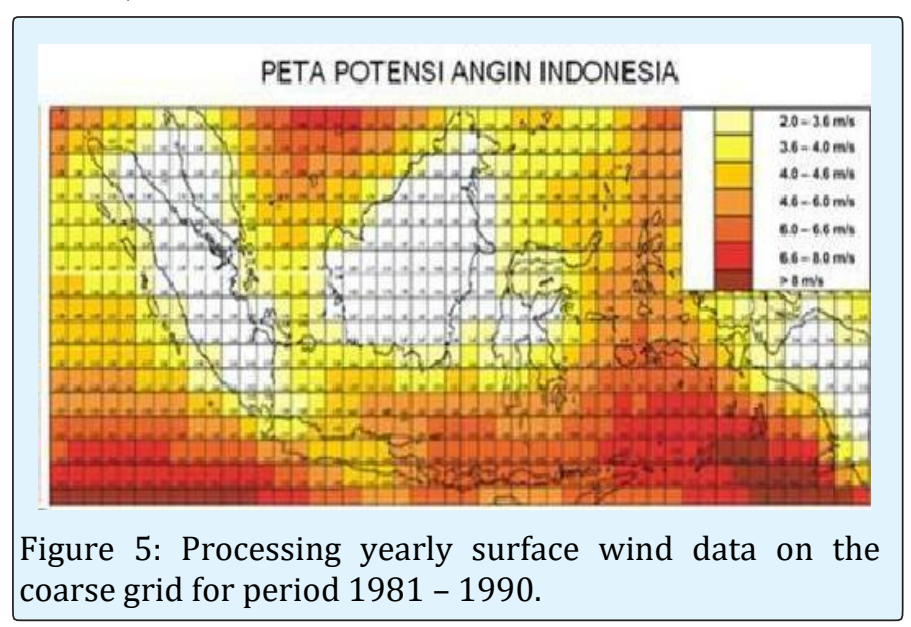

This figure is quantity of the wind speed in the gridding term from mean wind for the period 1981 - 1990 obtained from Meteorological and Geophysical Agency (BMG). From this figure may give the potential area of power wind energy to be used for the electricity, the potential area with the strong wind more than 8 meter/second (the strongest) would be over southeast Moluccas area and the second step of strongest wind would be over southern Moluccas area that it is deep waters condition. Then areas of southwest and eastern of Java including Madura island have the wind speed yearly ranging 4.6-6 meter/second area of Bali up to East Nusa Tenggara, central and north Moluccas have the speed ranging $6-6.6$ meter/second and area. The areas of Northwest Banda Aceh, Northeast Celebes Island have the speed ranging 3.6 - 4 meter/second. Others may have less than 2 meter/second. 
This findings should explore further with consider of the local effect such as terrain, mountain and coastal area. As the local effect may also affect the regional wind in terms of the sea/land breeze and valley/mountain wind. Those local effects may be considered for obtaining steady and sustaining wind flow to be used the power of the electricity. This study is just initial effort to investigate further based upon the meteorological point of view to find out the potential wind area for the power of electricity [4-6].

Summary

From the theoretical meteorology, Indonesia archipelago lies in the tropical area with Northerly and Southerly winds from both hemisphere to meet as the so called the Inter Tropical Convergence Zone or Doldrums (axis of calm wind). In reality Indonesia as the maritime continent between the two oceans and two continent of the so called maritime continent area such that the area has unique wind system of seasonal wind system (monsoonal wind). In this monsoonal wind will have wind shift as the calm wind over the equatorial line (0 degree latitude both South/North).

The wind starts to blow if there will be pressure gradient force, this gradient will have value if there are differences between two consecutive places. So that if the inner area of Indonesia archipelago with almost homogenous surface pressure (low pressure area), the wind flow may be calm wind. Differ with outer side area especially over the southern area with more than 10 degrees latitude (South), this area is away from the equator line and it has usually bigger pressure gradient than northern hemisphere with not more than 8 degrees latitude (North). From this point, it can be investigated that southern area is favorable for the developing of the wind power energy.

The further exploration involves the processing yearly data on the grid size $1 \times 1$ degree latitude \& longitude, the yearly data may give the same result that southern hemisphere of Indonesia to be favorable area for the developing wind power energy. The best place would be over eastern Nusa Tenggara up to South Eastern of Moluccas. The area of Moluccas from North- South is favorable area for developing the wind power energy.

\section{References}

1. Archer Cristina, Jacobson Mark (2008) International Energy Agency: Evaluation of Global Wind Power.

2. Badan Meteorologi dan Geofisika (BMG) (1998) Pola Hujan dan Angin Musim di Indonesia.

3. Intergovernmental Panel on Climate Change (2007) Natural Forcing of the Climate System.

4. Fundamental of Physical Geography 2nd (Edn.).

5. Lejiang Y, Zhong S, Bian X, Warren E (2016) Climatology and trend of wind power resources and its surrounding regions: a revisit using Climate Forecast System Reanalysis data. Int. J. Climatology 36(5): 1097-1188.

6. Neubert T, Rycroft M, Farges T, Blanc E, Arnold N, et al. (2008) Recent result from studies of electric discharges in the mesosphere. Surv in Geophys 29(2): 71-137.

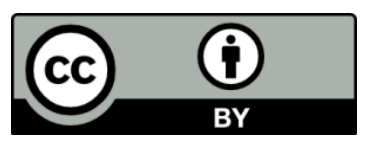

